Please do not remove this page

RMIT

UNIVERSITY

\title{
Experimental determination of low-cost servomotor reliability for small unmanned aircraft applications
}

Sarson-Lawrence, Jarrow; Sabatini, Roberto; Clothier, Reece; Gardi, Alessandro

https://researchrepository.rmit.edu.au/esploro/outputs/9921862192301341/filesAndLinks?institution=61RMIT_INST\&index=null

Sarson-Lawrence, J., Sabatini, R., Clothier, R., \& Gardi, A. (2014). Experimental determination of low-cost servomotor reliability for small unmanned aircraft applications. Applied Mechanics and Materials, 629, 202-207. https://doi.org/10.4028/www.scientific.net/AMM.629.202

Document Version: Accepted Manuscript

Published Version: https://doi.org/10.4028/www.scientific.net/AMM.629.202

Repository homepage: https://researchrepository.rmit.edu.au

(c) Trans Tech Technologies

Downloaded On 2023/04/26 19:28:34 +1000 
Thank you for downloading this document from the RMIT Research Repository.

The RMIT Research Repository is an open access database showcasing the research outputs of RMIT University researchers.

RMIT Research Repository: http://researchbank.rmit.edu.au/

\section{Citation:}

Sarson-Lawrence, J, Sabatini, R, Clothier, R and Gardi, A 2014, 'Experimental determination of low-cost servomotor reliability for small unmanned aircraft applications', Applied Mechanics and Materials, vol. 629, pp. 202-207.

See this record in the RMIT Research Repository at:

https://researchbank.rmit.edu.au/view/rmit:24987

Version: Accepted Manuscript

Copyright Statement: (c) Trans Tech Technologies

Link to Published Version:

http://dx.doi.org/10.4028/www.scientific.net/AMM.629.202 


\title{
Experimental Determination of Low-Cost Servomotor Reliability for Small Unmanned Aircraft Applications
}

\section{Jarrow Sarson-Lawrence ${ }^{1}$, Roberto Sabatini ${ }^{1, a}$, Reece Clothier $^{1}$ and Alessandro Gardi ${ }^{1}$}

\author{
${ }^{1}$ School of Aerospace, Mechanical and Manufacturing Engineering \\ University, Melbourne, VIC 3000, Australia \\ aroberto.sabatini@rmit.edu.au
}

\begin{abstract}
Keywords: Reliability, Low-Cost Sensors, Servomotors, COTS, Mini Unmanned Aircraft (UA).
\end{abstract}
Abstract. One of the key challenges of designing low-cost Unmanned Aircraft Systems (UAS) is to ensure acceptable and certifiable reliability factors for the adopted Commercial-off-the-Shelf (COTS) components since their reliability is often not quantified. In this paper the experimental results obtained for quantifying the reliability of mini Unmanned Aircraft (UA) servomotors (by recording their time-to-failure on a defined set of test runs) are presented. The Weibull prediction model is adopted for quantitative analysis and the associated key mathematical models. The methodology adopted for performing the reliability analysis including the test bench setup used for the experiments is described. The results indicate a level of reliability expected for low-cost servos. Such servos could be used for low-risk UAS operations (e.g., small UA operating over sparsely populated regions) and where the economics of the business case permitted higher loss rates.

\section{Introduction}

Unmanned Aircraft (UA) are being used in an increasing number of civil and military applications. In order to integrate them into civil airspace, reliability has to be ensured for the components used. Reliability is a key factor in the certification process to assess the safety of the UA. At present, the number of failures per flight of UA is higher than those of conventional manned aircraft [1]. A phenomenal number of UA mishaps are caused by flight control systems, propulsion and operator errors [2]. There has been an increasing number of Commercial-off-the-Shelf (COTS) UA components like autopilots, airframes and sensors [3]. The assessment of the overall UA reliability is critical since many of these COTS products lack essential reliability information. The focus of this research is on evaluating the reliability of the components employed in mini UA. Mini UA are typically below $2.4 \mathrm{~kg}$, capable of being hand launched and larger than micro UA, which have a wing span below $150 \mathrm{~mm}$ [4]. Table 1 summarises the currently adopted UA types based on Maximum Take-Off Weight (MTOW).

Table 1. UA types based on MTOW [5].

\begin{tabular}{|c|c|c|}
\hline MTOW [kg] & Type & Description \\
\hline Up to 0.2 & Micro & $\begin{array}{l}\text { Most countries do not regulate this category since they pose } \\
\text { less danger to human life and nature }\end{array}$ \\
\hline Up to 2.4 & Mini & \multirow{2}{*}{$\begin{array}{l}\text { Typically corresponding to converted R/C model aircraft, } \\
\text { whose operations were initially based on AC } 91-57\end{array}$} \\
\hline Up to 28 & Small & \\
\hline Up to 336 & Light/Ultra-light & $\begin{array}{c}\text { Airworthiness certification for this category are ultra-light } \\
\text { (FAR Part 103), Light-Sport Aircraft (LSA) (Order 8130) and } \\
\text { normal aircraft (FAR Part 23) }\end{array}$ \\
\hline Up to 4,000 & Normal & $\begin{array}{l}\text { MTOW corresponding to general aviation aircraft } \\
\text { (FAR Part 23) }\end{array}$ \\
\hline Up to 47,580 & Large & $\begin{array}{l}\text { MTOW corresponding to transport aircraft category } \\
\text { (FAR Part 25) }\end{array}$ \\
\hline
\end{tabular}




\section{Servomotors and Reliability}

Reliability is defined by the US military as the probability that an item will perform its intended function for a specified interval under stated conditions [7]. Reliability has been analysed in detail for a number of applications as in [7,8]. Reliability can be quantified in a number of ways including failure probability, failure rate and Mean-Time-Between-Failures (MTBF). MTBF is defined as the average time a system will be in operation until a failure occurs or the reciprocal of the failure rate. The MTFB is given by:

$$
M T B F=\frac{\text { operating Time }}{\text { Failures }}
$$

The overall reliability of a system is affected by the reliability of its subsystems. Reliability tests broadly fall under three categories namely; development and demonstration testing, qualification and acceptance testing and operational testing [9]. Test to failure is adapted as the testing method and all the components are tested until they failed. The feedback of the adopted servomotors arm position is a width-modulated pulse signal [6]. Brushless DC motors used in the servomotors have a higher reliability than their brushed counterparts since the brushes are prone to erosion on the commutator. The servomotors being tested as part of this research are used for the Flight Control System (FCS) of the mini UA.

\section{Failure Rate Model}

The Weibull model is one of the most commonly used lifetime distributions in reliability engineering [10]. The primary advantage of the Weibull analysis it that it provides accurate failure estimation even with relatively small samples [11]. The reliability function is given by:

$$
R(t)=e^{-(\eta \cdot t)^{\beta}}
$$

The Cumulative Density Function (CDF) and Probability Density Function (PDF) are expressed as:

$$
\begin{aligned}
& C D F=1-e^{-(t / \eta)^{\beta}} \\
& P D F=\frac{\beta}{\eta}\left(\frac{t}{\eta}\right)^{\beta-1} e^{-(t / \eta)^{\beta}}
\end{aligned}
$$

where $\beta$ is the Weibull shape parameter, $\eta$ is the Weibull scale parameter corresponding to the time when $63 \%$ of the sample fail and $t$ is the time frame. Weibull distributions can flexibly represent a wide range of other distributions including exponential, normal, Rayleigh, Poisson and Binomial [12]. However, a single Weibull curve is not able to represent all the three stages namely increasing, decreasing and constant value, of a Bathtub-shaped Failure Rate (BFR) [13]. The US military handbook on reliability prediction of electronic equipment [7] uses two Weibull parameters to model equipment reliability and the prediction failure rate, $\lambda_{p}$ [failures $/ 10^{6}$ hours] is expressed as:

$$
\lambda_{p}=\left(\frac{t^{2}}{\alpha_{B}{ }^{3}}+\frac{1}{\alpha_{W}}\right) \times 10^{6}
$$

where $\alpha_{B}$ is the Weibull characteristic life for motor bearings and $\alpha_{W}$ is the Weibull characteristic life for motor windings. Assuming the standard of $2.3 \times 10^{-5}$ failures/flight hour, equal to a MTBF of $43478 \mathrm{hrs}$ time, we obtain $\lambda_{p}=9.5810^{-6}$ failures $/ 10^{6}$ hours. The failure is defined as the condition at which the servomotor is no longer able to lift the weights at the set frequency. The failure mode is determined via visual inspection once the failure has occurred. Bearing failures produce a compete loss of function to the servomotor. Ball bearings and sleeve bearings are the most common type of bearings used in motors. Worn bearings, vibration, over-currents and unclean potentiometers are some of the causes for the failures to occur, in addition to wear and tear of the components. 
This is the author pre-publication version. This paper does not include the changes arising from the revision, formatting and publishing process. The final paper that should be used for referencing is:

J. Sarson-Lawrence, R. Sabatini, R. Clothier, A. Gardi, "Experimental Determination of Low-Cost Servomotor Reliability for Small Unmanned Aircraft Applications", Applied Mechanics and Materials, vol. 629, pp. 202-207, Trans Tech Publications, 2014. DOI: $10.4028 /$ www.scientific.net/AMM.629.202

\section{Methodology}

Success run testing is performed when all components are expected to survive the testing with zero failures. Success run testing is used to validate a particular reliability criterion, when no failures are expected to occur during the time constrained testing. The number of samples needed for a success run test is determined and based on a binomial distribution with $p$ representing the probability of failure, the probability of obtaining $k$ bad items and $(n-k)$ good items is given by [10]:

$$
f(k)=\frac{n !}{k !(n-k) !} p^{k}(1-p)^{n-k}
$$

Reasonable values of $80 \%$ reliability at a confidence $C$ level of $50 \%$ were assumed, leading to a sample size of seven with the actual confidence level at $52 \%$ and the confidence level expressed as:

$$
\begin{aligned}
& R=I-p \\
& C=1-\sum_{i=0}^{k} \frac{N !}{i !(N-i) !} R^{N-i}(1-R)^{i}
\end{aligned}
$$

All components were run continuously until failure and time to failure is recorded. A dedicated MATLAB $^{\mathrm{TM}}$ script allowed variations for inputs to the servomotor, namely the cycle frequency and update rate. The number of runs is dependent on the power requirements. In conditions wherein a number of runs were required for a component, the order is randomised to reduce the effect of any unknown variables. Ambient temperature was also logged due to its effect on insulation life and increasing the resistance of conductors. The highest update rate was chosen to provide the servomotors with a more fluid continuous motion while in cycle. By operating the servomotors at their maximum voltage the servomotors were operated under a higher stress. This reduced the time required to conduct the experiment as the time to failure is a function of stress. The cycle frequency of the servomotors is selected as the lowest frequency possible to allow the servomotors to reach the entire range of angle values, even under load conditions. The load conditions were chosen to represent the forces that could be expected on the mini UA and the test torque, $\tau$ is given by:

$$
\tau=\frac{\left(\frac{\sin (S) \tan (S)}{\tan (n)}\right) M P C^{2} L V^{2}}{4 R T}
$$

where $S=30^{\circ}$ is the control surface angle from neutral, $n=45^{\circ}$ is the servomotor arm angle from neutral, $M=28.6 \mathrm{~g} / \mathrm{mol}$ is the molecular weight of air, $\mathrm{p}$ is the air pressure, $C=60 \mathrm{~mm}$ is the chord, $L=440 \mathrm{~mm}$ is the length of the control surface, $V=40 \mathrm{~m} / \mathrm{s}$ is the airspeed, $T$ is the temperature in ${ }^{\circ} \mathrm{C}$ and $R$ is the ideal gas constant and equals $8.31451 \mathrm{JK}^{-1} \mathrm{~mol}^{-1}$. Adopting the characteristics of a small-size UA like the JAVELIN [14] a torque $(\tau)$ of $497 \mathrm{~g} . \mathrm{cm}$ is obtained for a max speed of $40 \mathrm{~m} / \mathrm{s}$. The obtained aileron torque and surface deflection are compared as illustrated in Fig. 1. The overall assumptions associated with the defined methodology are: ambient conditions including sea level, zero humidity and temperature of $12^{\circ} \mathrm{C}$, zero accelerations and angular velocities, the angle of attack of the wing, stab, fuse and the control surfaces is zero, control linkages have zero offset at hinge line, frictionless control mechanisms, mass-balanced surfaces and nil aerodynamic counterbalances.

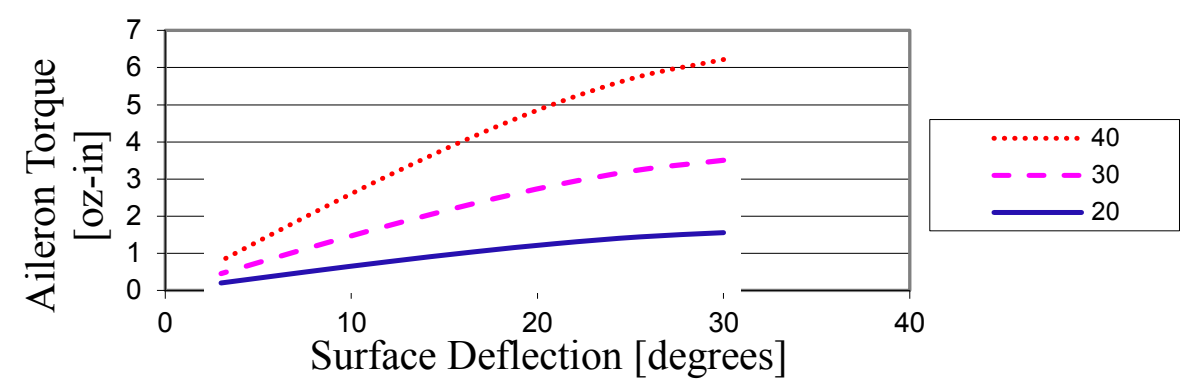

Fig. 1. Comparison of aileron torque [oz-in] and surface deflection [degrees]. 


\section{Test bench}

A section of stock right-angle aluminium bar attached to a wooden board was used as the test rig for the servomotor. A terminal block was also attached to the board secured to a table by G-clamps for connecting the power supply and motor signal source. The servomotor test rig, illustrated in Fig. 2, was designed to enable the servomotors to be attached on their side and thus allowed it to lift the loads up and down the side of the table.

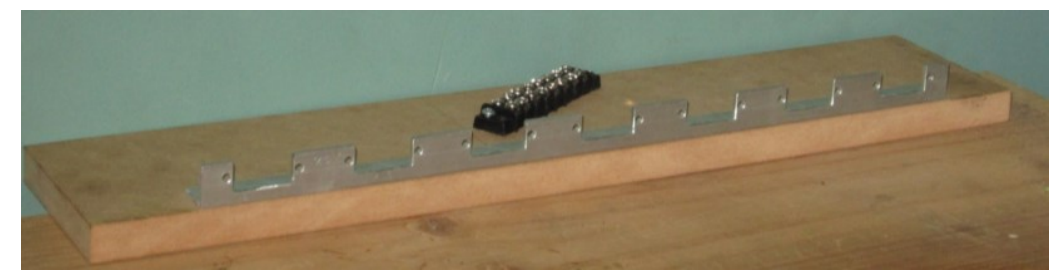

Fig. 2. Test bench.

Seven HK15148B digital servomotors [15] were used for the test as illustrated in Fig. 3 and its specifications and dimensions are detailed in Table 2. Additionally, a GW Instek SPS3610, a Manson NP-9615, $5 \mathrm{~m}$ of $5.2 \mathrm{~kg}$ finishing wire, seven weights of $500 \mathrm{~g}$ each, a microcontroller, a laptop computer, a webcam, three breadboard jumper wires and three crocodile clips were used. A webcam with a resolution of $640 \times 480$ pixels was used to monitor the test and was controlled by a python script. Three Frames Per Second (FPS) rate is chosen based on the parameters of servomotor period $(1 \mathrm{~s})$ and the size of the video file used.

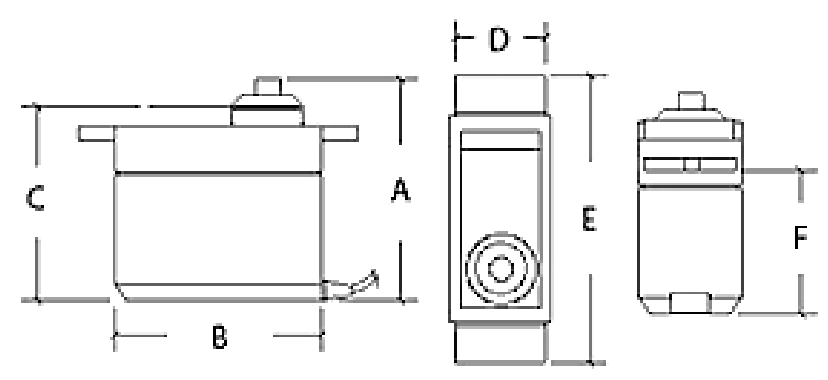

Table 2. Servomotor data [15].

Fig. 3. Side, top and front view of the HK15148B digital servomotor [15].

\begin{tabular}{|c|c|}
\hline Parameter & Value \\
\hline Weight $[\mathrm{g}]$ & 19 \\
\hline Torque $[\mathrm{kg}]$ & 2.8 \\
\hline Speed [s/60deg] & 0.14 \\
\hline A [mm] & 33 \\
\hline B [mm] & 28 \\
\hline C [mm] & 30 \\
\hline D [mm] & 13 \\
\hline E [mm] & 40 \\
\hline F $[\mathrm{mm}]$ & 19 \\
\hline
\end{tabular}

\section{Results}

Recorded failure times and the corresponding time-to-failure are listed in Table 3. The resulting logarithmic plot of the Weibull model fit is illustrated in Fig. 4. The exact time of failure for $2^{\text {nd }}, 5^{\text {th }}$ and $11^{\text {th }}$ servomotors are only known between $\pm 3.5 \mathrm{hr}$ and $\pm 4.5 \mathrm{hr}$ due to an excessive change in lightning conditions that affected the precise data acquisition. $\beta=0.7986$ and $\eta=25.71$ are obtained within $95 \%$ confidence interval. The calculated MTBF for the servomotors is $29.124 \mathrm{hrs}$.

Table 3. Time to failure.

\begin{tabular}{|c|c|c|c|c|}
\hline $\begin{array}{c}\text { Servo } \\
\text { motor }\end{array}$ & $\begin{array}{c}\text { Start time } \\
{[\mathbf{2 5 . 0 9 . 2 0 1 3}]}\end{array}$ & $\begin{array}{c}\text { Recorded failure } \\
\text { [Date and Time] }\end{array}$ & $\begin{array}{c}\text { Time to failure } \\
\text { [hrs] }\end{array}$ & $\begin{array}{c}\text { Resultant time to } \\
\text { failure [hrs] }\end{array}$ \\
\hline 1 & $15: 26: 48$ & $28.09 .2013 \quad 00: 26 \sim 09: 07$ & $56 \mathrm{~h} 40 \mathrm{~m} \sim 65 \mathrm{~h} 20 \mathrm{~m}$ & $60.17 \pm 3.5$ \\
\hline 2 & $15: 26: 48$ & $25 / 26.09 .2013 \quad 22: 34 \sim 8: 09$ & $7 \mathrm{~h} 7 \mathrm{~m} \sim 16 \mathrm{~h} 42 \mathrm{~m}$ & $11.87 \pm 4.5$ \\
\hline 3 & $15: 26: 48$ & $25.09 .2013 \quad 19: 36: 27$ & $4 \mathrm{~h} 10 \mathrm{~m}$ & 4.17 \\
\hline 4 & $15: 26: 48$ & $29.09 .2013 \quad 13: 49$ & $95 \mathrm{~h} 22 \mathrm{~m}$ & 95.37 \\
\hline 5 & $15: 26: 48$ & $25 / 26.09 .2013 \quad 22: 34 \sim 8: 09$ & $7 \mathrm{~h} 7 \mathrm{~m} \sim 16 \mathrm{~h} 42 \mathrm{~m}$ & $11.87 \pm 4.5$ \\
\hline 6 & $15: 26: 48$ & $25.09 .2013 \quad 16: 10$ & $0 \mathrm{~h} 43 \mathrm{~m}$ & 0.728 \\
\hline 7 & $15: 26: 48$ & $26.09 .2013 \quad 11: 08$ & $19 \mathrm{~h} 41 \mathrm{~m}$ & 19.69 \\
\hline
\end{tabular}




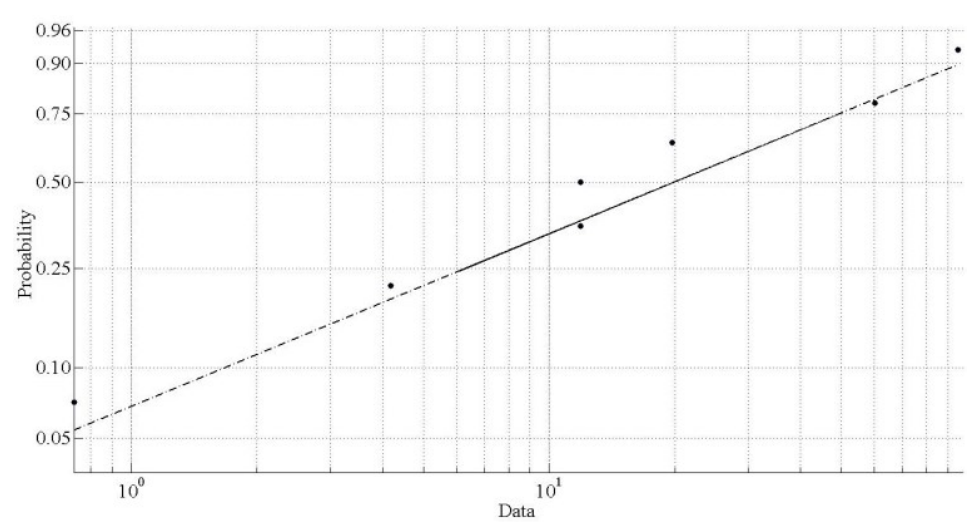

Fig. 41. Weibull model fit.

Fig. 5 (a) and (b) illustrate the resulting CDF and PDF for the tested servomotors respectively.

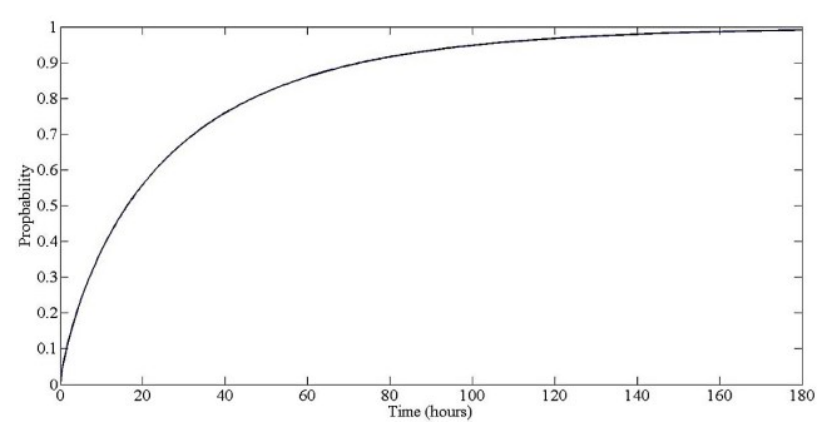

(a) $\mathrm{CDF}$

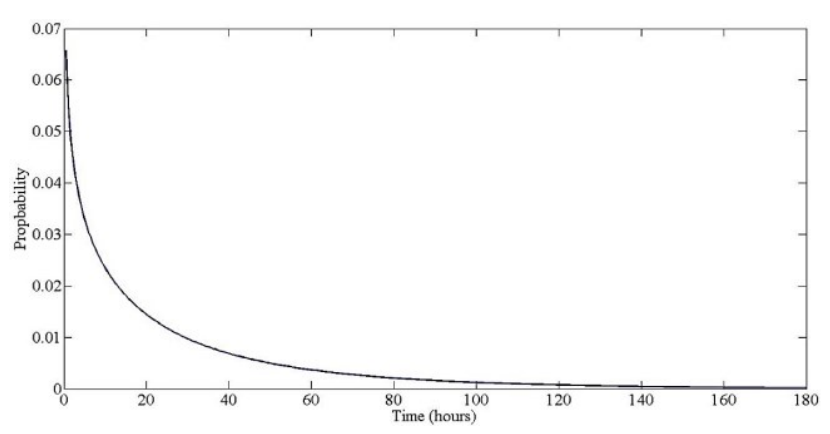

(b) PDF

Fig. 5. Servomotor CDF and PDF.

Analysis of the failed servomotors provides insight on the reason for the failures. The scale parameter of the Weibull function being below one indicates that the failure rate decreases over time and that there is significant quick failure rate in the servomotors with five out of seven failing in less than 24 hours. The resulting MTBF for the servomotors is not compatible with the requirements for manned aircraft and significantly lower than the $43478 \mathrm{hrs}$ estimate based on military handbook [7].

Reliability is one of a number of factors influencing the risk UAS pose to people and property on the ground. Assuming a servo failure is "catastrophic" (i.e., resulting in a loss of control of the air vehicle) then the reliability results indicate a level of reliability expected for low-cost servos. Such servos could be used for low-risk UAS operations (e.g., small UAS operating over sparsely populated regions) and where the economics of the business case permitted higher platform loss rates.

\section{Conclusions and Future Work}

The experimental activities performed for assessing the reliability of low-cost COTS servomotors employed in mini Unmanned Aircraft (UA) were presented. The time-to-failure was recorded with the servomotors subject to severe loads for the entire range of operations. A Weibull model was adopted to obtain the failure rate profile. Additionally, the methodology and the test bench used were presented. Although the low cost COTS servomotors are not compatible with the applicable standards for certification, it is deduced that the reliability parameters could be sufficient to fulfil the requirements of low-risk UA operations (e.g., small UA flying over sparsely populated areas). Future research will address the introduction of COTS components in a variety of avionic and flight systems including Sense-and-Avoid [17], electrical power generation/distribution and storage, laser obstacle avoidance and monitoring [18], integrated navigation and guidance [19] and integrity augmentation systems. 
This is the author pre-publication version. This paper does not include the changes arising from the revision, formatting and publishing process. The final paper that should be used for referencing is:

J. Sarson-Lawrence, R. Sabatini, R. Clothier, A. Gardi, "Experimental Determination of Low-Cost Servomotor Reliability for Small Unmanned Aircraft Applications", Applied Mechanics and Materials, vol. 629, pp. 202-207, Trans Tech Publications, 2014. DOI: 10.4028/www.scientific.net/AMM.629.202

\section{References}

[1] R. Weibel and R.J. Hansman, Safety Considerations for Operation of Different Classes of UAVs in the NAS, Proceedings of the $3^{\text {rd }}$ AIAA Unmanned Unlimited Technical Conference, Workshop and Exhibit, pp. 341-351. (2004) DOI: 10.2514/6.2004-6421

[2] M. Dermentzoudis, Establishment of Models and Data Tracking for Small UAV Reliability, Master's thesis, Naval Postgraduate School, Monterey, California, USA. (2004)

[3] K.K. Bhamidipati, D. Uhlig and N. Neogi, Engineering Safety and Reliability into UAV Systems: Mitigating the Ground Impact Hazard, AIAA. (2007) DOI: 10.2514/6.2007-6510

[4] B. Clough, Unmanned Aerial Vehicles: Autonomous Control Challenges, A Researcher's Perspective, Journal of Aerospace Computing, Information, and Communication, vol. 2, pp. 327 347. (2005) DOI: $10.2514 / 1.5588$

[5] K. Dalamagkidis, K.P. Valavanis and L.A. Piegl, On Unmanned Aircraft Systems Issues, Challenges and Operational Restrictions Preventing Integration into the National Airspace System, Progress in Aerospace Sciences, vol. 44, pp. 503-519. (2008) DOI: 10.1016/j.paerosci.2008.08.001

[6] N. Pinckney, Pulse-Width Modulation for Microcontroller Servomotor Control, Potentials, IEEE, vol. 25, pp. 27-29. (2006)

[7] Military Handbook, Reliability Prediction of Electronic Equipment, Department of Defence, USA. (1991)

[8] R.E. Barlow, Mathematical Reliability Theory: From the Beginning to the Present Time, Mathematical and Statistical Methods in Reliability, ed. B. H. Lindqvist and K. A. Doksum, vol. 7, pp. 3-15, World Scientific, London, UK. (2003)

[9] B.S. Dhillon, Reliability, Quality, and Safety for Engineers, CRC Press, London, UK. (2004)

[10] A. Kleyner, Reliability Demonstration in Product Validation Testing, The Handbook of Performability Engineering, ed. K.B. Misra, Springer-Verlag, London, UK. (2008)

[11] R.B. Abernethy, The New Weibull Handbook, $5^{\text {th }}$ ed., North Palm Beach, FL, USA. (2001)

[12] D.N.P. Murthy, M. Xie and R. Jiang, Weibull Models, Wiley, New York, USA. (2003)

[13] M. Xie, C.D. Lai and D.N.P. Murthy, Weibull Related Distributions for the Modelling of Bathtub Shaped Failure Rate Functions, Mathematical and Statistical Methods in Reliability, vol. 7, ed. B.H. Lindqvist and K.A. Doksum, World Scientific, London, pp. 283-299. (2003)

[14] M. Burston, R. Sabatini, A. Gardi and R. Clothier, Reverse Engineering of a Fixed Wing Unmanned Aircraft 6-DoF Model on Laser Scanner Measurements, in proceedings of IEEE International Workshop on Metrology for Aerospace, Benevento, Italy, pp. 144-149. (2014)

[15] HobbyKing.com HK15148B Digital Servomotor 19g/2.8kg/0.14s http://www.hobbyking.com/ hobbyking/store/_38591_HK15148B_Digital_Servomotor_19g_2_8kg_0_14s_AUS_Warehouse _.html. (Accessed $26^{\text {th }}$ May 2014)

[16] EASA, Certification Specification 25 (CS25), Amendment $3^{\text {rd }}$ ed. (2007)

[17] S. Ramasamy, R. Sabatini and A. Gardi, Avionics Sensor Fusion for Small Size Unmanned Aircraft Sense-and-Avoid, in proceedings of IEEE International Workshop on Metrology for Aerospace, Benevento, Italy, pp. 271-276. (2014)

[18] R. Sabatini, A. Gardi and S. Ramasamy, A Laser Obstacle Warning and Avoidance System for Manned and Unmanned Aircraft, in proceedings of IEEE International Workshop on Metrology for Aerospace, Benevento, Italy, pp. 616-621. (2014)

[19] R. Sabatini, C. Bartel, A. Kaharkar, T. Shaid and S. Ramasamy, Navigation and Guidance System Architectures for Small Unmanned Aircraft Applications, International Journal of Mechanical, Industrial Science and Engineering, 8(4), pp. 733-752, WASET. (2014) 